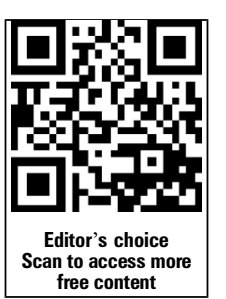

can to access more free content

- Additional material is published online only. To view please visit the journal online (http://dx.doi.org/10.1136/ oemed-2014-102615).

1 Department of Epidemiology, University of North Carolina, Chapel Hill, North Carolina, USA

${ }^{2}$ Department of Medicine, Division of Nephrology and Hypertension, University of North Carolina, Chapel Hill, North Carolina, USA

${ }^{3}$ Department of Biological Sciences, Center for Human Health and the Environment North Carolina State University, Raleigh, North Carolina, USA ${ }^{4}$ Epidemiology Branch/Chronic Disease Epidemiology Group, National Institute of

Environmental Health Sciences, Research Triangle Park, North Carolina, USA

\section{Correspondence to} Dr Dale P Sandler, Epidemiology Branch/Chronic Disease Epidemiology Group National Institute of

Environmental Health Sciences, P.O. Box 12233, MD A3-05,

111 T.W. Alexander Drive Research Triangle Park, NC 27709, USA;

sandler@niehs.nih.gov

Received 10 November 2014 Revised 2 May 2015

Accepted 22 June 2015

Published Online First

15 July 2015

\section{Sinked}

http://dx.doi.org/10.1136/ oemed-2014-102615

\section{CrossMark}

To cite: Lebov JF, Engel LS, Richardson $\mathrm{D}$, et al. Occup Environ Med 2016;73:3-12.

\title{
Pesticide use and risk of end-stage renal disease among licensed pesticide applicators in the Agricultural Health Study
}

\author{
Jill F Lebov, ${ }^{1}$ Lawrence $S$ Engel, ${ }^{1}$ David Richardson, ${ }^{1}$ Susan L Hogan, ${ }^{2}$ \\ Jane A Hoppin, ${ }^{3}$ Dale P Sandler ${ }^{4}$
}

\begin{abstract}
Objectives Experimental studies suggest a relationship between pesticide exposure and renal impairment, but epidemiological evidence is limited. We evaluated the association between exposure to 39 specific pesticides and end-stage renal disease (ESRD) incidence in the Agricultural Health Study, a prospective cohort study of licensed pesticide applicators in lowa and North Carolina.
\end{abstract}

Methods Via linkage to the US Renal Data System, we identified 320 ESRD cases diagnosed between enrolment (1993-1997) and December 2011 among 55580 male licensed pesticide applicators. Participants provided information on use of pesticides via self-administered questionnaires. Lifetime pesticide use was defined as the product of duration and frequency of use and then modified by an intensity factor to account for differences in pesticide application practices. Cox proportional hazards models, adjusted for age and state, were used to estimate associations between ESRD and: (1) ordinal categories of intensity-weighted lifetime use of 39 pesticides, (2) poisoning and high-level pesticide exposures and (3) pesticide exposure resulting in a medical visit or hospitalisation.

Results Positive exposure-response trends were observed for the herbicides alachlor, atrazine, metolachlor, paraquat, and pendimethalin, and the insecticide permethrin. More than one medical visit due to pesticide use $(\mathrm{HR}=2.13 ; 95 \% \mathrm{Cl} 1.17$ to 3.89$)$ and hospitalisation due to pesticide use $(\mathrm{HR}=3.05 ; 95 \% \mathrm{Cl}$ 1.67 to 5.58) were significantly associated with ESRD. Conclusions Our findings support an association between ESRD and chronic exposure to specific pesticides, and suggest pesticide exposures resulting in medical visits may increase the risk of ESRD.

Clinical trial registration Clinicaltrials.gov NCT00352924.

\section{INTRODUCTION}

In 2011, over 600000 US residents were receiving treatment for end-stage renal disease (ESRD), a lifethreatening condition requiring dialysis or kidney transplant for survival. Although much research has been conducted on clinical precursors to ESRD, such as diabetes and hypertension, research is limited on the impact of environmental and occupational factors. Literature on the nephrotoxic effects of pesticides in humans is extremely limited, and mainly comes from case reports of both fatal and non-fatal

\section{What this paper adds}

- Much is known about clinical risk factors for end-stage renal disease (chronic kidney disease requiring dialysis or kidney transplant for survival), but research on environmental risk factors for kidney disease is limited.

- In this study of male pesticide applicators, risk of end-stage renal disease increased with increasing cumulative exposure to several pesticides, including the herbicides alachlor, metolachlor, paraquat and pendimethalin, and the insecticide permethrin.

- Risk of end-stage renal disease was significantly greater for pesticide applicators who reported multiple doctor visits due to pesticide use and hospitalisation due to pesticide use, compared with those who reported no medical visits due to pesticide use.

- Exposure to certain pesticides may increase the risk of end-stage renal disease; however, additional studies are needed to support these findings.

pesticide poisoning, which have described acute nephrotoxicity with a variety of pesticide classes. ${ }^{1-5}$ Most of the evidence regarding nephrotoxicity of pesticides is restricted to experimental animal studies. Renal damage and dysfunction have been observed in experimental animal studies with exposure to specific pesticides in a dose-dependent ${ }^{6-9}$ and/or exposure duration-dependent ${ }^{7-11}$ manner. A variety of pesticide classes have been shown to cause renal damage and dysfunction in animals, including organophosphate, ${ }^{6} 9$ organochlorine, ${ }^{10}{ }^{12}$ carbamate $^{13}$ and pyrethroid ${ }^{14}$ insecticides and triazine ${ }^{15}$ and chlorophenoxy ${ }^{8}$ herbicides.

The impact of long-term pesticide exposure on human kidney function remains largely unknown. Generally, studies conducted in El Salvador, Nicaragua and Sri Lanka indicate an elevated prevalence of chronic kidney disease (CKD) among agricultural workers ${ }^{16-19}$ compared to those who have never worked in agriculture, particularly among male agricultural workers; ${ }^{20}$ pesticide exposure is postulated to be a contributor to kidney disease in these regions, but existing evidence has not confirmed this hypothesis. ${ }^{16-18}$ These studies lack 
specificity with regard to pesticide type and have not been able to adequately assess the long-term effects of chronic low-level or acute high-level pesticide exposure on ESRD risk. To our knowledge, the only study to assess pesticide exposure and ESRD found self-reported work in a place with frequent or daily exposure to insect or plant spray to be associated with increased ESRD risk. $^{21}$

The Agricultural Health Study (AHS) is the largest prospective study of pesticide applicators in the USA. Linking the AHS to the US Renal Data System (USRDS) provides a unique opportunity to evaluate the relationship between pesticide use and ESRD risk. Using this linkage, we evaluated associations between chronic and acute pesticide exposure and ESRD risk.

\section{METHODS}

\section{Population and case definition}

Details of the AHS design have been described previously. ${ }^{22}$ Briefly, the AHS recruited private pesticide applicators (mainly farmers) $(\mathrm{N}=52$ 394) in North Carolina and Iowa, and commercial pesticide applicators $(\mathrm{N}=4916)$ in Iowa who applied for or renewed a restricted-use pesticide license between 1993 and 1997. At the licensing facility, each pesticide applicator was asked to complete a brief enrolment questionnaire. Participating applicators were also given a packet of additional questionnaires to complete at home and mail back (take-home questionnaire). Approximately $82 \%$ of eligible private applicators and $47 \%$ of eligible commercial applicators enrolled in the study. Farm workers were not included in the AHS. At enrolment, applicators provided information on lifetime pesticide use and pesticide use practices, demographic characteristics, lifestyle factors, farm information, and medical history in a self-administered questionnaire. ${ }^{22}$ Of enrolled applicators, $44 \%$ also completed the take-home questionnaire with additional questions about medical history and pesticide use. ${ }^{23}$ Questionnaires are available on the AHS web site: http://aghealth.nih.gov/collaboration/ questionnaires.html.

We identified ESRD cases diagnosed between study enrolment and end of follow-up (31 December 2011) through linkage with the USRDS. The USRDS collects data on all ESRD cases in the USA through Medical Evidence Form CMS-2728, which is required for all new patients with ESRD, regardless of Medicare eligibility. The USRDS derives the first ESRD service date (FSD) by taking the earliest of: (1) the date of the start of dialysis for chronic renal failure, as reported on the Medical Evidence form; (2) the date of a kidney transplant or (3) the date of the first Medicare dialysis claim. ${ }^{24}$ The FSD was used to estimate age at ESRD diagnosis. Date of death was obtained from state mortality files and the National Death Index. Because the distribution of ESRD risk factors differs by gender, and because few applicators were female, we excluded female applicators $(\mathrm{N}=1562 ; 2.7 \%)$ from this analysis. We also excluded applicators under age $18(\mathrm{~N}=127 ;<1.0 \%)$ and ESRD cases diagnosed prior to enrolment $(\mathrm{N}=42 ; 11.5 \%$ of cases). This left us with 55580 participants for analyses of enrolment questionnaire variables, and 24565 participants for analyses of take-home questionnaire variables.

\section{Exposure assessment}

Information provided on the enrolment and take-home questionnaires was used to estimate lifetime pesticide exposure. Though information on pesticide use is available in later phases of the AHS study, we limited these analyses to enrolment information because recent exposure was anticipated to have a minor impact on ESRD risk, given the typical decades-long progression of this disease from chronic stage 1 to ESRD, and recent exposure information was not available for all participants. Participants provided information on years of use (duration) and average days per year of use (frequency) for 22 pesticides on the enrolment questionnaire. Duration and frequency of use data were obtained on the take-home questionnaire for 28 additional pesticides. For each pesticide, an intensity-weighted lifetime exposure metric was generated by multiplying lifetime-days of use (product of duration and frequency of use) by an intensity score that accounts for differences in exposure resulting from variation in pesticide application methods, repair of pesticide application equipment, and use of personal protective equipment. ${ }^{25}$ The intensity score algorithm was developed using AHS-specific pesticide exposure monitoring data, in conjunction with expert judgment from published studies on pesticide exposure, including information from the Pesticide Handlers Exposure Database. ${ }^{25}$ We used intensity-weighted lifetime-days as our primary exposure metric. Owing to the relatively small number of cases, we used the distribution of use among cases to create cut points for intensity-weighted lifetime use of specific pesticides. For pesticides used by $\geq 15 \%$ of cases, we categorised non-zero intensity-weighted lifetime-days into tertiles with non-users as the referent group. For less frequently used pesticides, non-zero intensity-weighted lifetime-days of use were split at the median $(<$ median vs $\geq$ median), with non-users as the referent group. Analyses were restricted to pesticides for which there were at least five cases in each exposure stratum. This left 39 pesticides available for analyses.

To assess overall pesticide use, we evaluated risk related to duration, frequency and lifetime-days of use of any pesticide. Duration and frequency of use were categorised into three levels (lowest category of use (referent), >lowest category of use to the median value, and $>$ median). Cumulative lifetime-days of use was categorised into quartiles.

Participant report of medical visits due to pesticide use (enrolment questionnaire), unusually high personal exposure to any pesticide (take-home questionnaire), and doctor-diagnosed pesticide poisoning (take-home questionnaire) were also evaluated in relation to ESRD risk.

\section{Statistical analysis}

We used Cox proportional hazards models to calculate HRs for risk of ESRD, using age as the timescale and adjusting for state as a covariate in all models. Person-time was accrued from the date of study enrolment until the earliest of ESRD diagnosis, death, or the end of study follow-up (31 December 2011). The proportional hazards assumption was evaluated for each model by entering a product term (exposure of interest $\times$ time on study) into each model. A product term coefficient which differed significantly from zero $\left(\chi^{2} \mathrm{p}\right.$ value $\left.<0.10\right)$ indicated a potential violation of the proportional hazards assumption.

Private and commercial applicators were analysed together because there were too few ESRD cases among the latter to analyse them separately. Race and education level were identified as additional potential confounders through directed acyclic graph analyses (DAGs) informed by a review of prior literature. Because adjustment for these factors did not substantially change HR estimates, and power was reduced due to incomplete ascertainment of education and race data, we did not adjust for these factors in the final analyses. Although diabetes and body mass index (BMI) were associated with ESRD risk in this and other studies, ${ }^{26} 27$ it was unknown whether these conditions affected pesticide use, and it is possible that use of specific pesticides may increase the risk of diabetes and $\mathrm{BMI},{ }^{28-31}$ which 
may be on the causal pathway to ESRD. HR estimates obtained from models adjusted for diabetes and BMI were not meaningfully different from crude estimates; therefore, these two conditions were not included in final adjusted models. Hypertension was not adjusted for because it is largely asymptomatic and therefore is unlikely to have affected pesticide use practices. Additionally, in our study, there was no association between cumulative pesticide use and hypertension (data not shown).

To assess potential confounding by other pesticides, we examined pairwise correlations between pesticides that were strongly (HR in any strata $\geq 1.5$ or $\leq 0.65$ ) or significantly associated with ESRD in single pesticide-adjusted exposure-response models. For pesticides with a Spearman correlation coefficient $\geq 0.3$, we constructed models with both pesticides, using the intensityweighted variables included in the main analyses. For pesticides that were correlated with more than one pesticide, we first evaluated each pesticide pair and then added correlated pesticides one at a time into subsequent models. We assessed model fit using Akaike information criteria (AIC) and selected that with the lowest AIC as the final model.

To assess linear exposure-response trends in intensityweighted lifetime use, we used within-category medians as the score for each level of use for each chemical. Exposure-response trends were also evaluated for duration, frequency and cumulative lifetime-days of use of any pesticide, and number of doctor visits related to pesticide use.

ESRD is the final stage of CKD, which is often debilitating in later stages of the disease. Cases may have already experienced the effects of CKD prior to study enrolment, which could have influenced their pesticide use. If those with earlier stages of renal disease have reduced exposure due to modified application practices, effect estimates for specific pesticide use would be biased towards the null. This bias is commonly referred to as the healthy worker survivor effect. ${ }^{32}$ To evaluate the potential for this effect to influence our findings, we repeated analyses, excluding person-time for all participants for the first 5 years after enrolment under the assumption that ESRD cases diagnosed within 5 years following study enrolment likely had poor renal health at enrolment.

To evaluate whether patterns of association were consistent across states, we entered a product term for state into pesticide use models for those pesticides for which there were at least five cases in each stratum of use in both states.

We used the AHS data set releases P1REL201209, P3REL201209.00, and AHSREL201304.00. All statistical analyses were done using SAS V.9.3 (Cary, North Carolina, USA).

\section{RESULTS}

Of the 55580 participants eligible for analysis, 320 (308 private and 12 commercial) were diagnosed with ESRD over an average 15.7-year follow-up period (incidence rate: 36.6 ESRD cases per 100000 person-years). Among the subset of 24565 participants who returned the take-home questionnaire, there were 136 cases (incidence rate: 35.1 ESRD cases per 100000 person-years). ESRD incidence was significantly higher in North Carolina compared with Iowa, regardless of age, which follows the pattern of ESRD incidence in the general population. ${ }^{24}$ In age-adjusted and state-adjusted models, education level of high school or lower and obesity at enrolment, were associated with increased risk of ESRD (table 1). Self-reported doctor diagnosis of diabetes, high blood pressure and kidney disease were significantly associated with increased risk of ESRD. There was a suggestive but non-significant association between pack-years of cigarettes smoked and ESRD, but applicator type, number of years living on a farm, and alcohol consumption at enrolment were not associated with ESRD risk.

More than one doctor visit due to pesticide use and hospitalisation due to pesticide use were both significantly associated with ESRD with a significant trend observed for increasing number of pesticide-related doctor visits ( $p$ for trend $=0.038$ ) (table 2). ESRD risk was not associated with either self-reported unusually high personal pesticide exposure or pesticide poisoning, though only five ESRD cases reported a pesticide poisoning diagnosis. No exposure-response relationships were observed for duration and frequency of general pesticide use (data not shown), or for cumulative lifetime-days of general pesticide use (table 2).

In intensity-weighted cumulative use analyses, positive associations were observed primarily among herbicides (table 3). ESRD risk was associated with the highest tertile of intensityweighted use of five herbicides: atrazine, metolachlor, alachlor, paraquat and pendimethalin, compared to no use. We observed a significant ( $\mathrm{p}$ for trend $<0.05$ ) exposure-response trend with increasing use levels for all these herbicides. Although exposure-response trends were not seen for the herbicides petroleum oil or imazethapyr, ever use of these chemicals was significantly associated with risk $(\mathrm{HR}=1.63 ; 95 \%$ CI 1.11 to 2.41 and $\mathrm{HR}=1.46$; $95 \%$ CI 1.08 to 1.99 , respectively; data not shown). The proportional hazards assumption held for all exposures of interest.

Among non-herbicide pesticides, associations for the insecticides coumaphos, parathion and phorate (organophosphates), aldicarb (carbamate), chlordane (organochlorine), and for the fungicide metalaxyl were elevated (ie, >1.6), but did not reach statistical significance (table 3). A significant positive exposure-response trend was present for permethrin (for crops) ( $\mathrm{p}$ for trend $=0.0311$ ).

In analyses of correlated pesticides, we found 13 pesticides to be correlated (ie, had a Spearman correlation coefficient $\geq 0.30$ ) with at least one other pesticide. Adjustment for correlated pesticides resulted in reduced overall sample size due to missing data for each chemical. Adjusted estimates were generally similar in magnitude and direction, but were attenuated and less precise. Patterns of exposure-response also did not change. After adjustment for correlated pesticides, the association between ESRD risk and the top tertile of intensity-weighted use remained significant only for pendimethalin. The association with the top tertile of alachlor remained elevated but no longer significantly associated with ESRD risk after adjustment for correlated pesticides. We did not observe a correlation coefficient $\geq 0.3$ for the following pesticides: 2,4,5-Trichlorophenoxyacetic acid (2,4,5-T) 2,4,5T, chlorimuron ethyl, paraquat, petroleum oil, coumaphos, fonofos, parathion and permethrin (crops) (data not shown).

In a sensitivity analysis, evaluating the potential for a 'healthy worker survivor effect', we excluded 53 cases that were diagnosed with ESRD within 5 years after enrolment and 277900 person-years. The greatest per cent reductions of case numbers were observed in the 'None' use category for all pesticides. In general, associations for intensity-weighted lifetime-use were in the same direction and of very similar magnitude compared with estimates in the main analyses. Of note, age-adjusted and state-adjusted estimates for the highest quantile of intensityweighted coumaphos use became significant $(\mathrm{HR}=1.81,95 \%$ CI 1.03 to 3.17 , and we observed a significant positive exposure-response trend for chlordane ( $p$ for trend=0.0177) (see online supplementary table S1).

Results did not change substantially when we restricted analyses to private applicators (data not shown). Thirteen pesticides 
Table 1 Association between ESRD and demographic and medical conditions among private and commercial applicators, adjusted for age and state, Agricultural Health Study (1993-1997)

\begin{tabular}{|c|c|c|c|}
\hline Variable (at enrolment) & $\begin{array}{c}\text { Non-cases } \\
(\mathrm{N}=55260) \\
\mathrm{N}(\%)\end{array}$ & $\begin{array}{c}\text { ESRD cases } \\
(\mathrm{N}=320) \\
\mathrm{N}(\%)\end{array}$ & HR $(95 \% \mathrm{Cl})$ \\
\hline \multicolumn{4}{|l|}{ State (where enrolled)* } \\
\hline lowa & $35943(65.0)$ & $134(41.9)$ & \\
\hline North Carolina & $19317(35.0)$ & $186(58.1)$ & 2.02 (1.61 to 2.53$)$ \\
\hline \multicolumn{4}{|l|}{ Applicator type* } \\
\hline Private & $50575(91.5)$ & $308(96.3)$ & \\
\hline Commercial & $4685(8.5)$ & $12(3.7)$ & $0.75(0.42$ to 1.35$)$ \\
\hline \multicolumn{4}{|l|}{ Age category (years) } \\
\hline $18-30$ & $6306(11.4)$ & $12(3.8)$ & \\
\hline $31-49$ & $27380(49.6)$ & $58(18.1)$ & $1.15(0.62$ to 2.15$)$ \\
\hline $50-69$ & $18924(34.3)$ & $210(65.6)$ & $6.04(3.38$ to 10.81$)$ \\
\hline$\geq 70$ & $2650(4.8)$ & $40(12.5)$ & $10.04(5.25$ to 19.20$)$ \\
\hline \multicolumn{4}{|l|}{ Race } \\
\hline Caucasian & $52763(97.3)$ & $273(85.3)$ & \\
\hline Other & $1440(2.7)$ & $47(14.7)$ & 4.42 (3.18 to 6.13$)$ \\
\hline \multicolumn{4}{|l|}{ Education level } \\
\hline High school or less & $30495(57.6)$ & $230(75.7)$ & \\
\hline More than high school & $22452(42.4)$ & $74(24.3)$ & 0.65 (0.50 to 0.85$)$ \\
\hline \multicolumn{4}{|c|}{ Number years lived or worked on a farm $\dagger$} \\
\hline $0-20$ & $2181(10.0)$ & $10(7.9)$ & \\
\hline $21-30$ & $2928(13.4)$ & $13(10.2)$ & $1.43(0.62$ to 3.28$)$ \\
\hline$>30$ & $16668(76.5)$ & $104(81.9)$ & 0.90 (0.46 to 1.75$)$ \\
\hline \multicolumn{4}{|c|}{ Number of days per month drink alcohol in the last year } \\
\hline 0 & $16504(31.9)$ & $147(52.1)$ & \\
\hline $1-23$ & $31833(61.5)$ & $121(42.9)$ & 0.86 (0.66 to 1.11$)$ \\
\hline$\geq 24$ & $3447(6.7)$ & $14(5.0)$ & 0.78 (0.45 to 1.36$)$ \\
\hline \multicolumn{4}{|c|}{ Number of pack-years smoked } \\
\hline None & $28059(53.8)$ & $124(43.5)$ & \\
\hline $1-11$ & $10956(21.0)$ & $45(15.8)$ & $0.80(0.57$ to 1.13$)$ \\
\hline $12-30$ & $8708(16.7)$ & $67(23.5)$ & $1.23(0.91$ to 1.66$)$ \\
\hline$>30$ & $4464(8.6)$ & $49(17.2)$ & $1.36(0.97$ to 1.91$)$ \\
\hline \multicolumn{4}{|l|}{ Body mass index $\left(\mathrm{kg} / \mathrm{m}^{2}\right)$} \\
\hline$<25$ & $9658(25.5)$ & $44(19.8)$ & \\
\hline $25-29.99$ & $19341(51.1)$ & $108(48.6)$ & 1.26 (0.89 to 1.79$)$ \\
\hline$\geq 30$ & $8823(23.3)$ & $70(31.5)$ & 2.00 (1.37 to 2.93$)$ \\
\hline \multicolumn{4}{|c|}{ Self-reported doctor diagnosis of } \\
\hline \multicolumn{4}{|l|}{ Diabetes } \\
\hline No & $49616(97.2)$ & $192(70.1)$ & \\
\hline Yes & $1411(2.8)$ & $82(29.9)$ & 8.78 (6.72 to 11.45$)$ \\
\hline \multicolumn{4}{|l|}{ High blood pressuret } \\
\hline No & $20081(83.6)$ & $52(39.4)$ & \\
\hline Yes & 3945 (16.4) & $80(60.6)$ & 4.66 (3.25 to 6.68$)$ \\
\hline \multicolumn{4}{|c|}{ Kidney disease (not counting kidney stones) } \\
\hline No & $50935(99.2)$ & $245(88.4)$ & \\
\hline Yes & $415(0.8)$ & $32(11.6)$ & 10.35 (7.14 to 15.02$)$ \\
\hline
\end{tabular}

had five exposed cases in each exposure stratum in both states, and were therefore included in analyses of interaction with state. P-values for interaction with state were consistently $>0.10$ (data not shown), suggesting no differences by state.

\section{DISCUSSION}

To the best of our knowledge, this is the first study to evaluate the association between ESRD risk and cumulative lifetime use of specific pesticides. Among pesticide applicators in the AHS, we found significant positive associations between intensityweighted use of several specific pesticides and ESRD; excluding cases that arose within 5 years after enrolment strengthened some of these associations, though estimates were less precise due to the reduction in sample size. This is also the first epidemiological study of ESRD risk associated with non-fatal pesticide poisoning, acute high-level exposure, and pesticide exposure requiring medical attention. Participants who reported doctor visits and hospitalisation due to pesticide use had a 
Table 2 Association between ESRD risk and acute and cumulative pesticide exposure, adjusted for age and state, among male pesticide applicators, Agricultural Health Study (1993-1997)

\begin{tabular}{|c|c|c|c|c|}
\hline Variable & $\begin{array}{c}\text { Non-cases } \\
(\mathrm{N}=55260) \\
N(\%)\end{array}$ & $\begin{array}{l}\text { ESRD cases } \\
\qquad \begin{array}{c}(\mathrm{N}=320) \\
\mathrm{N}(\%)\end{array}\end{array}$ & HR $(95 \% \mathrm{CI})$ & $p$ for trend \\
\hline \multicolumn{5}{|c|}{ Number of times ever visited a medical doctor due to pesticide use } \\
\hline None & $49764(93.4)$ & $272(91.3)$ & & \\
\hline Once & $2635(4.9)$ & $15(5)$ & $1.07(0.64$ to 1.8$)$ & \\
\hline \multirow[t]{2}{*}{ More than once } & $884(1.7)$ & $11(3.7)$ & 2.13 (1.17 to 3.89$)$ & \\
\hline & & & & 0.0384 \\
\hline \multicolumn{5}{|c|}{ Ever hospitalised due to pesticide use } \\
\hline No & $51619(98.9)$ & $275(96.2)$ & & \\
\hline Yes & $572(1.1)$ & $11(3.8)$ & 3.05 (1.67 to 5.58$)$ & \\
\hline \multicolumn{5}{|c|}{ Ever experienced unusually high personal pesticide exposure* } \\
\hline No & $20112(84.8)$ & $115(87.1)$ & & \\
\hline Yes & $3596(15.2)$ & $17(12.9)$ & $1.08(0.65$ to 1.81$)$ & \\
\hline \multicolumn{5}{|c|}{ Ever diagnosed with pesticide poisoning* } \\
\hline No & $23506(98.0)$ & $126(96.2)$ & & \\
\hline Yes & $484(2.0)$ & $5(3.8)$ & 1.59 (0.65 to 3.89$)$ & \\
\hline \multicolumn{5}{|c|}{ Cumulative lifetime-days personally mixed or applied pesticides } \\
\hline $0-64$ & $13850(27.1)$ & $78(28.0)$ & & \\
\hline $65-225$ & $15637(30.6)$ & $69(24.7)$ & $0.89(0.64$ to 1.24$)$ & \\
\hline $226-457$ & $7307(14.3)$ & $41(14.7)$ & $0.95(0.65$ to 1.39$)$ & \\
\hline \multirow[t]{2}{*}{$>457$} & $14314(28.0)$ & $91(32.6)$ & 1.07 (0.79 to 1.44$)$ & \\
\hline & & & & 0.4667 \\
\hline
\end{tabular}

significantly higher risk of ESRD diagnosis compared to those who did not, but we did not observe increased risk with applicator report of doctor-diagnosed pesticide poisoning or unusually high personal pesticide exposure.

Prior published epidemiological research on pesticide exposure and kidney disease is minimal. Results from several crosssectional studies evaluating the relationship between agricultural work and CKD suggest a potential association between agricultural work, particularly field work, and CKD prevalence. ${ }^{17} 20$ Studies that have evaluated overall pesticide exposure have found positive associations with CKD. ${ }^{17} 183334$ The only study to assess the relationship between ESRD risk and agricultural exposures observed an increased risk of ESRD among a large population of insured patients in the San Francisco Bay area who reported that they worked in a place with 'frequent or daily exposure to insect or plant spray' (unadjusted $\mathrm{HR}=1.78$; 95\% CI 1.36 to 2.34). ${ }^{21}$ By contrast, results from our analyses of general overall pesticide use did not show an association with ESRD; however, few participants in this licensed applicator cohort reported no pesticide use, and evaluation of overall pesticide use may obscure associations because only some pesticides appear to be associated with ESRD.

Epidemiologic studies of renal effects of specific pesticides are rare. Hernandez et $a l^{35}$ found no difference in serum creatinine levels among greenhouse workers with higher versus lower levels of apparent cholinesterase inhibition (used as a marker for organophosphate pesticide exposure). Serum levels of several organochlorine insecticides among patients with CKD were inversely associated with kidney function, potentially indicating a renal filtration deficiency resulting in an accumulation of organochlorine pesticides in the body. ${ }^{36}$ In our study, ESRD risk was elevated for three cholinesterase-inhibiting insecticides (the carbamate aldicarb and the organophosphates coumaphos and parathion), with a moderate positive trend observed for coumaphos. No associations were seen with organochlorine use, except for chlordane, which was significantly positively associated with ESRD risk in analyses excluding cases diagnosed within 5 years after enrolment. Glyphosate was recently partially banned in Sri Lanka due to its hypothesised association with kidney disease, though the ban has since been lifted. Studies that informed this partial ban suggested that glyphosate exposure leads to renal failure only when combined with high-level exposure to heavy metals. ${ }^{37}$ We found no evidence of an association between ESRD risk and glyphosate exposure.

Experimental evidence supports our findings of positive associations with exposure to the herbicides atrazine, alachlor, paraquat and pendimethalin, the insecticide permethrin, and the fungicide metalaxyl, with evidence of dose-response as well as renal damage and dysfunction at low dose levels. Glomerular lesions and renal tubular necrosis due to oxidative stress-induced cell damage have been observed in animal models with exposure to metalaxyl and paraquat, ${ }^{38} 39$ and kidney damage and dysfunction have been observed in rats exposed to atrazine ${ }^{15}$ and fish exposed to alachlor. ${ }^{40}$ There have been no reports of renal effects of pendimethalin among mammals; however, at least one formulation of pendimethalin contains monochlorobenzene as an inert ingredient, which has been shown to cause kidney damage in rats. ${ }^{41}$ Dose-related renal damage was observed among animals exposed to permethrin. ${ }^{42} 43$ Sub-acute tubulointerstitial and glomerular damage, such as that observed in animal studies with prolonged low dosing of pesticides, ${ }^{7}{ }^{11}$ can initiate a feed-forward loop of kidney injury and progressive loss of renal function. ${ }^{44}$ In humans, pesticide poisoning can lead to acute kidney injury, ${ }^{45}$ which has been associated with increased risk of subsequent CKD and ESRD. ${ }^{46} 47$

When we adjusted for correlated pesticides, we found that many estimates were attenuated, and alachlor was positively associated but no longer statistically significant. We lacked statistical 
Table 3 Intensity-weighted lifetime-days of use of specific pesticides and ESRD risk, adjusted for age and state, among male pesticide applicators in the Agricultural Health Study (1993-1997)

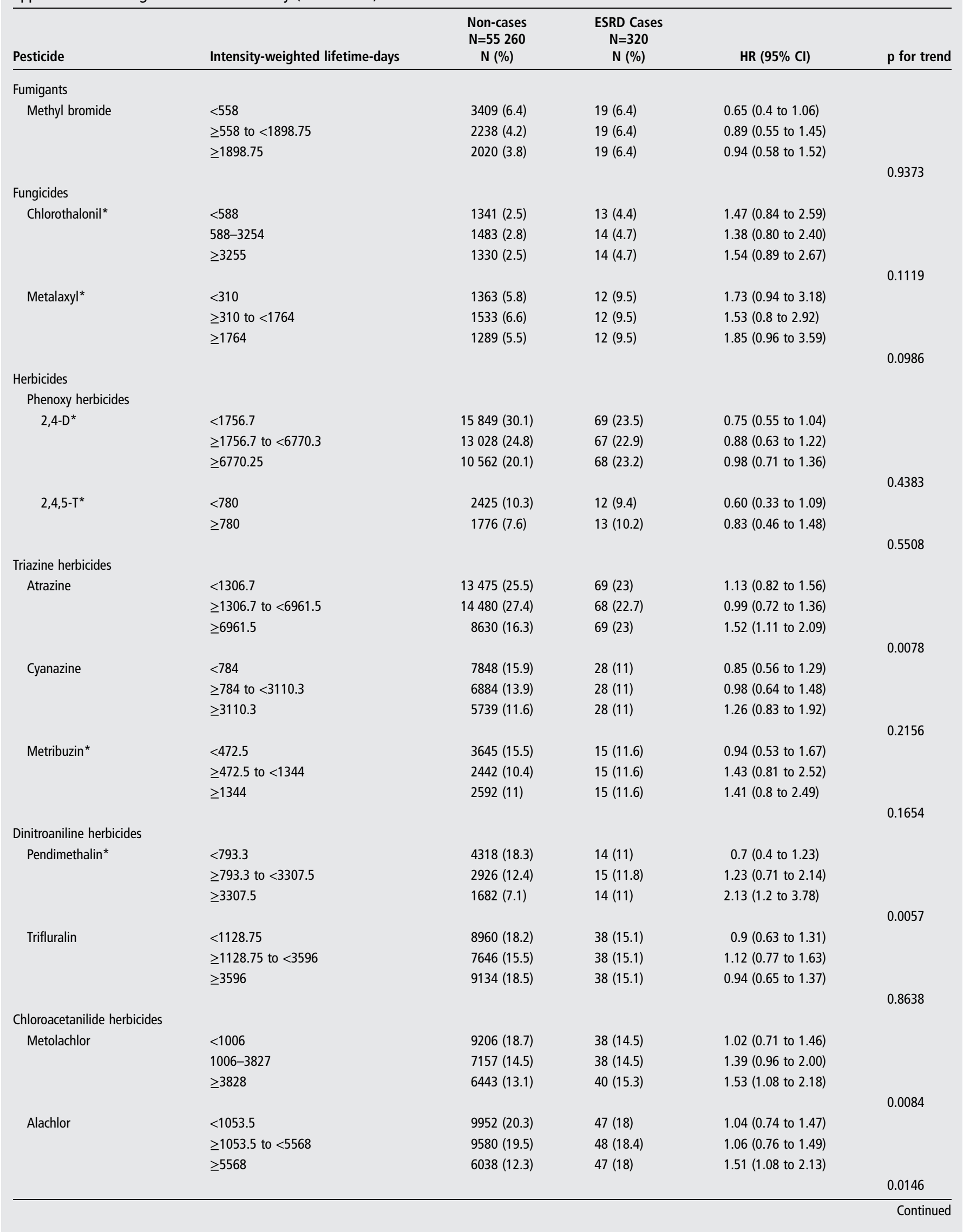


Table 3 Continued

\begin{tabular}{|c|c|c|c|c|c|}
\hline Pesticide & Intensity-weighted lifetime-days & $\begin{array}{c}\text { Non-cases } \\
\mathrm{N}=55260 \\
\mathrm{~N}(\%)\end{array}$ & $\begin{array}{c}\text { ESRD Cases } \\
\mathrm{N}=320 \\
\mathrm{~N}(\%)\end{array}$ & HR $(95 \% \mathrm{Cl})$ & $p$ for trend \\
\hline \multicolumn{6}{|l|}{ All other herbicides } \\
\hline \multirow[t]{4}{*}{ Dicamba } & $<490$ & $7153(14.6)$ & $32(12.4)$ & 0.99 (0.66 to 1.48$)$ & \\
\hline & $\geq 490$ to $<2766.75$ & $10203(20.8)$ & $31(12)$ & $0.69(0.46$ to 1.04$)$ & \\
\hline & $\geq 2766.75$ & $7290(14.9)$ & $32(12.4)$ & $1.06(0.7$ to 1.59$)$ & \\
\hline & & & & & 0.7387 \\
\hline \multirow[t]{4}{*}{ Chlorimuron-ethyl* } & $<385$ & $3516(14.9)$ & $13(10.1)$ & $0.93(0.52$ to 1.68$)$ & \\
\hline & $\geq 385$ to $<918.75$ & $1560(6.6)$ & $13(10.1)$ & $1.98(1.1$ to 3.55$)$ & \\
\hline & $\geq 918.75$ & $2516(10.7)$ & $13(10.1)$ & 1.21 (0.67 to 2.16$)$ & \\
\hline & & & & & 0.3560 \\
\hline \multirow[t]{4}{*}{ EPTC } & $<638$ & $4525(9.3)$ & $11(4.4)$ & $0.64(0.35$ to 1.19$)$ & \\
\hline & $\geq 638$ to $<2088$ & $2753(5.6)$ & $12(4.8)$ & $1.18(0.65$ to 2.13$)$ & \\
\hline & $\geq 2088$ & $2713(5.6)$ & $12(4.8)$ & 1.25 (0.69 to 2.24$)$ & \\
\hline & & & & & 0.3894 \\
\hline \multirow[t]{4}{*}{ Paraquat* } & $<708.75$ & $2040(8.7)$ & $11(8.5)$ & $1.05(0.56$ to 1.97$)$ & \\
\hline & $\geq 708.75$ to $<2334.5$ & $917(3.9)$ & $11(8.5)$ & $2.3(1.2$ to 4.41$)$ & \\
\hline & $\geq 2334.5$ & $970(4.1)$ & $11(8.5)$ & 2.15 (1.11 to 4.15$)$ & \\
\hline & & & & & 0.0164 \\
\hline \multirow[t]{4}{*}{ Petroleum oil* } & $<784$ & $1950(8.3)$ & $11(8.5)$ & 1.27 (0.68 to 2.38$)$ & \\
\hline & $784-2024$ & $1006(4.3)$ & $12(9.3)$ & $3.20(1.75$ to 5.85$)$ & \\
\hline & $\geq 2025$ & $1969(8.4)$ & $12(9.3)$ & $1.42(0.78$ to 2.59$)$ & \\
\hline & & & & & 0.1905 \\
\hline \multirow[t]{4}{*}{ Imazethapyr } & $<350$ & $6748(13.8)$ & $29(11.2)$ & $1.34(0.87,2.07)$ & \\
\hline & $\geq 350$ to $<882$ & $5034(10.3)$ & 30 (11.6) & $2.00(1.30,3.07)$ & \\
\hline & $\geq 882$ & $9178(18.7)$ & 30 (11.6) & $1.26(0.83,1.94)$ & \\
\hline & & & & & 0.3114 \\
\hline \multirow[t]{4}{*}{ Glyphosate } & $<609$ & 12231 & $72(24.1)$ & 0.93 (0.68 to 1.28$)$ & \\
\hline & $\geq 609$ to $<2821$ & $15245(28.8)$ & $73(24.4)$ & $0.72(0.53$ to 0.99$)$ & \\
\hline & $\geq 2821$ & $12474(23.6)$ & $71(23.7)$ & $0.87(0.63$ to 1.21$)$ & \\
\hline & & & & & 0.7095 \\
\hline \multirow[t]{3}{*}{ Butylate* } & $<918.75$ & 2985 (12.7) & $12(9.4)$ & 0.78 (0.43 to 1.43$)$ & \\
\hline & $\geq 918.75$ & $3140(13.4)$ & $13(10.2)$ & $0.87(0.48$ to 1.55$)$ & \\
\hline & & & & & 0.6294 \\
\hline \multicolumn{6}{|l|}{ Insecticides } \\
\hline \multicolumn{6}{|l|}{ Organochlorines } \\
\hline \multirow[t]{4}{*}{ Aldrin* } & $<326.7$ & $1292(5.5)$ & $12(9.8)$ & 1.27 (0.68 to 2.37$)$ & \\
\hline & $\geq 326.7$ to $<1019.2$ & $1196(5.1)$ & $11(9)$ & 1.21 (0.63 to 2.31$)$ & \\
\hline & $\geq 1019.2$ & $1227(5.2)$ & $12(9.8)$ & 1.23 (0.66 to 2.29$)$ & \\
\hline & & & & & 0.5243 \\
\hline \multirow[t]{4}{*}{ Chlordane* } & $<560$ & $2581(11)$ & $11(8.7)$ & 0.57 (0.3 to 1.06$)$ & \\
\hline & $\geq 560$ to $<1260$ & 838 (3.6) & $12(9.4)$ & 1.66 (0.9 to 3.04$)$ & \\
\hline & $\geq 1260$ & 841 (3.6) & $11(8.7)$ & 1.5 (0.8 to 2.82$)$ & \\
\hline & & & & & 0.0975 \\
\hline \multirow[t]{4}{*}{$\mathrm{DDT}^{*}$} & $<437.5$ & $1891(8.1)$ & $15(11.9)$ & $0.76(0.43$ to 1.33$)$ & \\
\hline & $\geq 437.5$ to $<2327.5$ & $1701(7.3)$ & $16(12.7)$ & $0.82(0.47$ to 1.41$)$ & \\
\hline & $\geq 2327.5$ & $1329(5.7)$ & $16(12.7)$ & $1.05(0.61$ to 1.83$)$ & \\
\hline & & & & & 0.7201 \\
\hline \multirow[t]{3}{*}{ Heptachlor* } & $<440$ & $1285(5.5)$ & $13(10.3)$ & 1.46 (0.8 to 2.67$)$ & \\
\hline & $\geq 440$ & $1383(5.9)$ & $13(10.3)$ & $1.29(0.71$ to 2.35$)$ & \\
\hline & & & & & 0.3898 \\
\hline \multirow{3}{*}{ Toxaphene* } & $<1006$ & $1554(6.6)$ & $8(6.5)$ & $0.69(0.34$ to 1.42$)$ & \\
\hline & $\geq 1006$ & $975(4.1)$ & $9(7.3)$ & 0.99 (0.49 to 1.99$)$ & \\
\hline & & & & & 0.9583 \\
\hline \multicolumn{6}{|l|}{ Organophosphates } \\
\hline Terbufos & $<840$ & 7169 (14.5) & $28(11)$ & 0.99 (0.66 to 1.5$)$ & \\
\hline & $\geq 840$ to $<2182.25$ & 4435 (9) & $28(11)$ & $1.46(0.97$ to 2.19$)$ & \\
\hline & $\geq 2182.25$ & 6766 (13.7) & $28(11)$ & $0.94(0.63$ to 1.41$)$ & \\
\hline & & & & & 0.9102 \\
\hline
\end{tabular}


Table 3 Continued

\begin{tabular}{|c|c|c|c|c|c|}
\hline Pesticide & Intensity-weighted lifetime-days & $\begin{array}{c}\text { Non-cases } \\
\mathrm{N}=55260 \\
\mathrm{~N}(\%)\end{array}$ & $\begin{array}{c}\text { ESRD Cases } \\
\mathrm{N}=320 \\
\mathrm{~N}(\%)\end{array}$ & HR $(95 \%$ Cl) & $p$ for trend \\
\hline \multirow[t]{4}{*}{ Fonofos } & $<672$ & $4129(8.3)$ & $11(4.3)$ & 0.62 (0.34 to 1.16$)$ & \\
\hline & $\geq 672$ to $<1837.5$ & $2770(5.6)$ & $11(4.3)$ & 0.91 (0.49 to 1.69$)$ & \\
\hline & $\geq 1837.5$ & $3366(6.8)$ & $11(4.3)$ & 0.7 (0.38 to 1.3$)$ & \\
\hline & & & & & 0.2736 \\
\hline \multirow[t]{4}{*}{ Chlorpyrifos } & $<437.5$ & $5953(13.1)$ & $28(10.6)$ & 0.83 (0.55 to 1.23 ) & \\
\hline & $\geq 437.5$ to $<2262$ & $7911(17.3)$ & $29(11)$ & 0.64 (0.43 to 0.95$)$ & \\
\hline & $\geq 2262$ & $5806(12.7)$ & $29(11)$ & 0.89 (0.6 to 1.32$)$ & \\
\hline & & & & & 0.5288 \\
\hline \multirow[t]{4}{*}{ Malathion* } & $<644$ & $6577(28.2)$ & $27(21.4)$ & 0.87 (0.54 to 1.42$)$ & \\
\hline & $\geq 644$ to $<1792$ & $3626(15.6)$ & $28(22.2)$ & 1.44 (0.89 to 2.32 ) & \\
\hline & $\geq 1792$ & $4344(18.7)$ & $28(22.2)$ & 1.02 (0.63 to 1.65$)$ & \\
\hline & & & & & 0.8744 \\
\hline \multirow[t]{3}{*}{ Parathion* } & $<1392$ & $1022(4.4)$ & $8(6.5)$ & 1.11 (0.53 to 2.29 ) & \\
\hline & $\geq 1392$ & $687(2.9)$ & $8(6.5)$ & 1.64 (0.79 to 3.43 ) & \\
\hline & & & & & 0.1856 \\
\hline \multirow[t]{3}{*}{ Diazinon* } & $<1260$ & $3183(13.6)$ & $12(9.5)$ & 0.61 (0.33 to 1.11$)$ & \\
\hline & $\geq 1260$ & $1703(7.3)$ & $13(10.3)$ & 1.07 (0.59 to 1.93$)$ & \\
\hline & & & & & 0.7867 \\
\hline \multirow[t]{4}{*}{ Phorate* } & $<437.5$ & $2632(11.2)$ & $12(9.9)$ & 0.88 (0.47 to 1.65$)$ & \\
\hline & $\geq 437.5$ to $<2688$ & $2781(11.9)$ & $11(9.1)$ & 0.75 (0.39 to 1.43 ) & \\
\hline & $\geq 2688$ & $1212(5.2)$ & $11(9.1)$ & $1.65(0.87$ to 3.1$)$ & \\
\hline & & & & & 0.135 \\
\hline \multirow[t]{3}{*}{ Coumaphos } & $<957$ & $2100(4.3)$ & $14(5.6)$ & 1.29 (0.75 to 2.22 ) & \\
\hline & $\geq 957$ & $1651(3.4)$ & $14(5.6)$ & 1.63 (0.95 to 2.79 ) & \\
\hline & & & & & 0.0689 \\
\hline \multirow[t]{3}{*}{ Dichlorvos } & $<3136$ & $2987(6.1)$ & $10(4.1)$ & 0.78 (0.41 to 1.47 ) & \\
\hline & $\geq 3136$ & $1682(3.4)$ & $10(4.1)$ & 1.41 (0.74 to 2.67 ) & \\
\hline & & & & & 0.2862 \\
\hline \multicolumn{6}{|l|}{ Pyrethroids } \\
\hline \multirow[t]{4}{*}{ Permethrin for crops } & $<420$ & $2917(6)$ & $11(4.3)$ & 0.99 (0.54 to 1.81$)$ & \\
\hline & $\geq 420$ to $<4002$ & $2847(5.8)$ & $11(4.3)$ & 0.9 (0.49 to 1.66$)$ & \\
\hline & $\geq 4002$ & $1160(2.4)$ & $11(4.3)$ & 2 (1.08 to 3.68$)$ & \\
\hline & & & & & 0.0311 \\
\hline \multirow[t]{3}{*}{ Permethrin for animals } & $<630$ & $2689(5.4)$ & $12(4.7)$ & 1.49 (0.83 to 2.68$)$ & \\
\hline & $\geq 630$ & $3245(6.5)$ & $13(5.1)$ & 1.33 (0.76 to 2.34 ) & \\
\hline & & & & & 0.2947 \\
\hline \multicolumn{6}{|l|}{ Carbamates } \\
\hline \multirow[t]{4}{*}{ Carbofuran } & $<696$ & $5740(11.7)$ & $21(8.4)$ & 0.65 (0.41 to 1.03 ) & \\
\hline & $696-2299$ & $3753(7.6)$ & $21(8.4)$ & 0.88 (0.56 to 1.39 ) & \\
\hline & $\geq 2300$ & $3210(6.5)$ & $22(8.8)$ & 1.06 (0.68 to 1.65 ) & \\
\hline & & & & & 0.7550 \\
\hline \multirow[t]{4}{*}{ Carbary| $\left.\right|^{*}$} & $<1006.3$ & $5034(21.6)$ & $18(14.4)$ & 0.55 (0.33 to 0.92 ) & \\
\hline & $\geq 1006.3$ to $<7280$ & $3212(13.8)$ & $18(14.4)$ & 0.65 (0.37 to 1.14$)$ & \\
\hline & $\geq 7280$ & $1574(6.7)$ & $18(14.4)$ & 1.05 (0.58 to 1.91$)$ & \\
\hline & & & & & 0.3252 \\
\hline \multirow[t]{3}{*}{ Aldicarb* } & $<1176$ & $835(3.5)$ & $7(5.5)$ & 1.54 (0.7 to 3.4 ) & \\
\hline & $\geq 1176$ & $899(3.8)$ & $8(6.3)$ & 1.83 (0.86 to 3.88 ) & \\
\hline & & & & & 0.1182 \\
\hline
\end{tabular}

*Indicates pesticide with duration and frequency information only available on the take-home questionnaire: $\mathrm{N}$ (non-cases)=24 429 and $\mathrm{N}$ (cases)=136.

DDT, dichlorodiphenyltrichloroethane; EPTC, s-ethyl dipropylthiocarbamate; ESRD, end-stage renal disease.

power to formally test interaction among specific pesticides. In addition, we saw significant associations for chemicals from a number of chemical groups. Given that there is no required renal toxicity testing for pesticides, we have no information regarding which chemicals we would expect to be associated with CKD. A large portion of commercial pesticide products are 'other ingredients' including solvents; therefore, it is possible that one or more of these 'other ingredients' are driving the risk observed here for unrelated chemicals. Unfortunately, we do not have access to what these 'other ingredients' are because they are regarded as confidential business information.

A significant positive exposure-response trend was observed for pesticide-related doctor visits, and participants who reported being hospitalised due to pesticide use had three times the risk of 
ESRD compared to those who did not. Although information about the route and type of pesticide involved in these exposures was not available, these findings support the hypothesis that frequent and/or severe pesticide exposures may increase the risk of ESRD. We did not see an association between pesticide poisoning or self-reported unusually high pesticide exposure and ESRD; however, power to detect an association was limited because information for those exposures was available only for participants who returned the take-home questionnaire, and pesticide poisoning was rarely diagnosed in the cohort. Pesticide poisoning is frequently under-diagnosed; ${ }^{48}$ thus, doctor visits or hospitalisation related to pesticide use may represent a more sensitive indicator for acute high-level exposure than pesticide poisoning diagnosis.

The study improves on prior research in several ways. First, we were able to evaluate associations of ESRD risk with a wide range of specific chemicals that vary in toxicity and extent of use. The prospective design of the study mitigates concerns about differential misclassification of exposure. Whereas prior studies were limited by small sample size and exposure to few chemicals, the large size of the AHS cohort allowed us to assess exposure-response trends for many individual pesticides. Also, use of a validated exposure-intensity metric ${ }^{25}$ allowed for a better estimate of each participant's likely pesticide exposure as opposed to non-specific pesticide use. Until now, the relationship between short-term high-level pesticide exposures and kidney disease has been evaluated only with respect to the immediate effects of pesticide poisonings. Here, we were able to evaluate measures of non-poisoning short-term high-level pesticide exposures, thereby providing an important contribution to the scientific literature regarding occupational risk factors for kidney disease. Additionally, the fact that almost all ESRD cases in the USA are captured in the USRDS reduces concerns about loss to follow-up or outcome misclassification.

Because exposure data were collected prior to disease onset and ESRD diagnosis data were obtained from a third party linkage rather than participant report, any exposure misclassification due to self-report is likely to be non-differential with respect to the outcome, which would bias estimates towards the null. Additionally, evidence suggests that report of pesticide exposure by AHS participants is reasonably reliable ${ }^{49}$ and plausible. ${ }^{50}$ The accuracy and reliability of reporting acute pesticide exposures has not been investigated.

Analyses of lifetime use of pesticides that were assessed only on the take-home questionnaire could be subject to selection bias if applicators who returned the take-home questionnaire were significantly different from those who did not by exposure or outcome, or by factors associated with the exposure or the outcome. State of enrolment, age and pesticide use characteristics were similar for those who returned the take-home questionnaire compared to those who did not, and the prevalence of ESRD was essentially the same for take-home questionnaire respondents as it was for non-respondents $(0.59 \%$ vs $0.57 \%)$. Still, differences in unmeasured factors remain a possibility, and we had limited power to evaluate associations between ESRD and lifetime use of the pesticides for which duration and frequency information was collected only on the take-home questionnaire.

Lifetime use estimates could also be biased if participants with prevalent pre-end-stage kidney disease modified their pesticide application practices in the period prior to enrolment. This 'healthy worker survivor effect' is a common problem in occupational health studies, including among pesticide applicators, ${ }^{51}$ frequently biasing estimates toward the null. ${ }^{32}$ Results of our sensitivity analysis suggest a minimal impact of this potential effect on HR estimates. The median time from enrolment to
ESRD diagnosis was 9.7 years. It is possible that unmeasured post-enrolment pesticide use may differ by case status; if recent exposures are stronger contributors to ESRD risk than pre-enrolment exposures, then our results would still be biased towards the null. However, progression of renal disease from chronic stage 1 to ESRD can take several decades; if pesticide use does contribute to kidney disease incidence, it is probable that this pathway would have been initiated prior to enrolment.

Because the AHS is a cohort of US farmers in North Carolina and Iowa, the risks for this cohort may be different from the risks experienced by farm workers in the USA or elsewhere. However, the AHS, with its detailed exposure characterisation, limited loss to follow-up over 20 years, and the ability to link to a populationbased kidney disease registry, provides important human data for evaluation of the role of pesticides and kidney disease.

Last, in these analyses, we estimated associations between a large number of exposures and ESRD. We did not employ statistical methods to adjust for multiple comparisons, such as the Bonferroni correction. Previous authors have cautioned against employing Bonferroni-type corrections in an epidemiological analysis of associations between multiple environmental or occupational exposures and disease, ${ }^{52-54}$ and such methods have largely fallen out of use in such settings because Bonferroni adjustments are concerned with testing of a general null hypothesis which is rarely of interest. Alternatives to Bonferroni methods exist for inference in settings where multiple exposure effects are estimated, including Bayesian methods; ${ }^{55}$ however, we have not employed such methods here, in preference for simply describing what statistical quantities have been estimated.

\section{CONCLUSIONS}

Our study provides evidence for an association between ESRD risk and chronic exposure to specific chemicals among pesticide applicators in Iowa and North Carolina. Results from this study also suggest that pesticide exposures resulting in medical visits increase the risk of incident ESRD, raising concerns that multiple high-level pesticide exposures may contribute to irreversible kidney damage and resultant disease. Efforts to better characterise the pathway between pesticide exposure and kidney disease should include assessments of earlier disease stages, rate of progression from CKD to ESRD, and other potential routes of pesticide exposure, such as spray drift and carry-home exposures. Caution should be taken in interpreting results of such studies when diagnosis dates or disease severity information is not available, because the healthy worker survivor effect may bias estimates towards the null. Additional epidemiological studies are needed to confirm the findings of our study, given the limited research on the role of pesticide exposure in the development of renal disease, and research on the direct renal toxicity of specific chemicals must be expanded to facilitate interpretation of epidemiological results.

Correction notice This paper has been amended since it was published Online First. The data for imazethapyr in Table 3 was misaligned and the cutpoints for cumulative use (left most column) were not there and these have now been added.

Acknowledgements The authors thank the participants of the AHS for their contribution to this research. They also thank Aaron Blair, Freya Kamel, Honglei Chen, Cynthia J Hines and Laura Beane Freeman for reviewing this manuscript, and Stuart Long at Westat for his assistance with data management.

Contributors JFL conducted the statistical analyses, interpreted the results and drafted the manuscript. As principal investigators of the Agricultural Health Study, DPS and JAH generated the underlying cohort study data, and conceived and designed the present study. DPS secured the funding for this project. LSE, DR, SLH, DPS and JAH provided general oversight for the project and contributed to the interpretation of results. Westat provided data management services. All authors 
provided critical insights and editing on drafts and read and approved the final manuscript.

Funding This research was supported in part by the Intramural Research Program of the NIH, National Institute of Environmental Health Sciences (ZO1 ES 049030) and by an $\mathrm{NIH}$, National Institute of Diabetes and Digestive and Kidney Diseases Ruth L Kirschstein National Research Service Award (NRSA) Institutional Research Training Grant (T32 DK 007750; PI RJ Falk).

Competing interests None declared.

Ethics approval Institutional Review Boards at UNC Chapel Hill, the NIH and the participating field sites.

Provenance and peer review Not commissioned; externally peer reviewed.

\section{REFERENCES}

1 Betrosian A, Balla M, Kafiri G, et al. Multiple systems organ failure from organophosphate poisoning. J Toxicol Clin Toxicol 1995;33:257-60.

2 Soloukides A, Moutzouris DA, Kassimatis T, et al. A fatal case of paraquat poisoning following minimal dermal exposure. Ren Fail 2007;29:375-7.

3 Wu IW. Wu MS, Lin JL. Acute renal failure induced by bentazone: 2 case reports and a comprehensive review. J Nephrol 2008;21:256-60.

4 Memis D, Tokatlioglu D, Koyuncu O, et al. Fatal aluminium phosphide poisoning. Eur J Anaesthesiol 2007:24:292-3.

5 Kim SJ, Gil HW, Yang JO, et al. The clinical features of acute kidney injury in patients with acute paraquat intoxication. Nephrol Dial Transplant 2009;24:1226-32.

6 Shah MD, lqbal M. Diazinon-induced oxidative stress and renal dysfunction in rats. Food Chem Toxicol 2010;48:3345-53.

7 Tripathi S, Srivastav AK. Nephrotoxicity induced by long-term oral administration of different doses of chlorpyrifos. Toxicol Ind Health 2010;26:439-47.

8 Uyanikgil Y, Ates U, Baka M, et al. Immunohistochemical and histopathological evaluation of 2,4-dichlorophenoxyacetic acid-induced changes in rat kidney cortex. Bull Environ Contam Toxicol 2009;82:749-55.

9 Poovala VS, Huang H, Salahudeen AK. Role of reactive oxygen metabolites in organophosphate-bidrin-induced renal tubular cytotoxicity. J Am Soc Nephrol 1999:10:1746-52.

10 Choudhary N, Sharma M, Verma P, et al. Hepato and nephrotoxicity in rat exposed to endosulfan. J Environ Biol 2003:24:305-8.

11 Sonne C, Wolkers H, Leifsson PS, et al. Organochlorine-induced histopathology in kidney and liver tissue from Arctic fox (Vulpes lagopus). Chemosphere 2008:71:1214-24.

12 Sobel ES, Gianini J, Butfiloski EJ, et al. Acceleration of autoimmunity by organochlorine pesticides in (NZB×NZW)F1 mice. Environ Health Perspect 2005;113:323-8.

13 Kaur B, Khera A, Sandhir R. Attenuation of cellular antioxidant defense mechanisms in kidney of rats intoxicated with carbofuran. I Biochem Mol Toxicol 2012;26:393-8.

14 Chargui I, Grissa I, Bensassi F, et al. Oxidative stress, biochemical and histopathological alterations in the liver and kidney of female rats exposed to low doses of deltamethrin (DM): a molecular assessment. Biomed Environ Sci 2012;25:672-83

15 Santa Maria C, Vilas MG, Muriana FG, et al. Subacute atrazine treatment effects on rat renal functions. Bull Environ Contam Toxicol 1986;36:325-31.

16 Orantes $\mathrm{CM}$, Herrera R, Almaguer $\mathrm{M}$ et al. Chronic kidney disease and associated risk factors in the Bajo Lempa region of El Salvador: Nefrolempa study, 2009. MEDICC Rev 2011:13:14-22.

17 Sanoff SL, Callejas L, Alonso CD, et al. Positive association of renal insufficiency with agriculture employment and unregulated alcohol consumption in Nicaragua. Ren Fail 2010;32:766-77.

18 O'Donnell JK, Tobey M, Weiner DE, et al. Prevalence of and risk factors for chronic kidney disease in rural Nicaragua. Nephrol Dial Transplant 2011;26:2798-805.

19 Bandara JM, Wijewardena HV, Bandara YM, et al. Pollution of River Mahaweli and farmlands under irrigation by cadmium from agricultural inputs leading to a chronic renal failure epidemic among farmers in NCP, Sri Lanka. Environ Geochem Health 2011;33:439-53.

20 Peraza S, Wesseling C, Aragon A, et al. Decreased kidney function among agricultural workers in El Salvador. Am J Kidney Dis 2012;59:531-40.

21 Hsu CY, Iribarren C, McCulloch CE, et al. Risk factors for end-stage renal disease: 25-year follow-up. Arch Intern Med 2009:169:342-50.

22 Alavanja MC, Sandler DP, McMaster SB, et al. The Agricultural Health Study. Environ Health Perspect 1996;104:362-9.

23 Tarone RE, Alavanja MC, Zahm SH, et al. The Agricultural Health Study: factors affecting completion and return of self-administered questionnaires in a large prospective cohort study of pesticide applicators. Am J Ind Med 1997;31:233-42.

24 United States Renal Data System. USRDS 2012 Annual Data Report: Atlas of Chronic Kidney Disease and End-Stage Renal Disease in the United States. Bethesda, MD: National Institute of Diabetes and Digestive and Kidney Diseases, 2012.
25 Coble J, Thomas KW, Hines CJ, et al. An updated algorithm for estimation of pesticide exposure intensity in the Agricultural Health Study. Int I Environ Res Public Health 2011;8:4608-22.

26 Bash LD, Astor BC, Coresh J. Risk of incident ESRD: a comprehensive look at cardiovascular risk factors and 17 years of follow-up in the Atherosclerosis Risk in Communities (ARIC) Study. Am J Kidney Dis 2010;55:31-41.

$27 \mathrm{Hsu} C \mathrm{CY}$, McCulloch CE, lribarren C, et al. Body mass index and risk for end-stage renal disease. Ann Intern Med 2006:144:21-8.

28 Lee DH, Steffes MW, Sjodin A, et al. Low dose organochlorine pesticides and polychlorinated biphenyls predict obesity, dyslipidemia, and insulin resistance among people free of diabetes. PLOS ONE 2011;6:e15977.

29 Lee DH, Steffes MW, Sjodin A, et al. Low dose of some persistent organic pollutants predicts type 2 diabetes: a nested case-control study. Environ Health Perspect 2010;118:1235-42.

30 Starling AP, Umbach DM, Kamel F, et al. Pesticide use and incident diabetes among wives of farmers in the Agricultural Health Study. Occup Environ Med 2014;71:629-35.

31 Montgomery MP, Kamel F, Saldana TM, et al. Incident diabetes and pesticide exposure among licensed pesticide applicators: Agricultural Health Study, 19932003. Am J Epidemiol 2008:167:1235-46.

32 Richardson D, Wing S, Steenland K, et al. Time-related aspects of the healthy worker survivor effect. Ann Epidemiol 2004;14:633-9.

33 Payan-Renteria R, Garibay-Chavez G, Rangel-Ascencio R, et al. Effect of chronic pesticide exposure in farm workers of a Mexico community. Arch Environ Occup Health 2012:67:22-30.

34 Raines N, Gonzalez M, Wyatt C, et al. Risk factors for reduced glomerular filtration rate in a Nicaraguan community affected by Mesoamerican nephropathy. MEDICC Rev 2014;16:16-22

35 Hernandez AF, Amparo Gomez M, Perez V, et al. Influence of exposure to pesticides on serum components and enzyme activities of cytotoxicity among intensive agriculture farmers. Environ Res 2006;102:70-6.

36 Siddharth M, Datta SK, Bansal S, et al. Study on organochlorine pesticide levels in chronic kidney disease patients: association with estimated glomerular filtration rate and oxidative stress. J Biochem Mol Toxicol 2012:26:241-7.

37 Jayasumana C, Gunatilake S, Senanayake P. Glyphosate, hard water and nephrotoxic metals: are they the culprits behind the epidemic of chronic kidney disease of unknown etiology in Sri Lanka? Int J Environ Res Public Health 2014;11:2125-47.

38 Paolini M, Mesirca R, Pozzetti L, et al. Biomarkers of effect in evaluating metalaxyl cocarcinogenesis. Selective induction of murine CYP $3 \mathrm{~A}$ isoform. Mutat Res 1996:361:157-64.

39 Adachi J, Tomita M, Yamakawa S, et al. 7-Hydroperoxycholesterol as a marker of oxidative stress in rat kidney induced by paraquat. Free Radic Res 2000;33:321-7.

40 Butchiram MS, Tilak KS, Raju PW. Studies on histopathological changes in the gill, liver and kidney of Channa punctatus (Bloch) exposed to Alachlor. J Environ Biol 2009:30:303-6.

41 Kluwe WM, Dill G, Persing R, et al. Toxic responses to acute, subchronic, and chronic oral administrations of monochlorobenzene to rodents. J Toxicol Environ Health 1985;15:745-67.

42 Anwar K. Effect of Permethrin Treatment on the Kidney of Newly Hatched Chick (Gallus domesticus). J Appl Sci 2003;3:317-30.

43 Guvenc D, Kabak Y, Atmaca E, et al. Examination of caspase-dependent apoptotic and necrotic changes in rat kidney exposed to different doses of permethrin. Biotech Histochem 2013:88:76-85.

44 Hodgkins KS, Schnaper HW. Tubulointerstitial injury and the progression of chronic kidney disease. Pediatr Nephrol 2012;27:901-9.

45 Reigart JR, Roberts JR, Agency USEP. Recognition and management of pesticide poisonings. Washington DC: US Environmental Protection Agency, 1999.

46 Coca SG, Singanamala S, Parikh CR. Chronic kidney disease after acute kidney injury: a systematic review and meta-analysis. Kidney Int 2012;81:442-8.

47 Ishani A, Xue JL, Himmelfarb J, et al. Acute kidney injury increases risk of ESRD among elderly. J Am Soc Nephrol 2009;20:223-8.

48 Roberts JR, Reigart JR. Recognition and management of pesticide poisonings. 6th edn. Washington DC: U.S. Environmental Protection Agency, 2013.

49 Blair A, Tarone R, Sandler D, et al. Reliability of reporting on life-style and agricultural factors by a sample of participants in the Agricultural Health Study from lowa. Epidemiology 2002;13:94-9.

50 Hoppin JA, Yucel F, Dosemeci M, et al. Accuracy of self-reported pesticide use duration information from licensed pesticide applicators in the Agricultural Health Study. J Expo Anal Environ Epidemiol 2002;12:313-18.

51 Gomez-Marin O, Fleming LE, Lee DJ, et al. Acute and chronic disability among U.S. farmers and pesticide applicators: the National Health Interview Survey (NHIS). J Agric Saf Health 2004;10:275-85.

52 Savitz DA, Olshan AF. Multiple comparisons and related issues in the interpretation of epidemiologic data. Am J Epidemiol 1995;142:904.

53 Perneger TV. What's wrong with Bonferroni adjustments. BMJ 1998;316:1236-8

54 Greenland S. Multiple comparisons and association selection in general epidemiology. Int J Epidemiol 2008;37:430-4.

55 MacLehose RF, Dunson DB, Herring AH, et al. Bayesian methods for highly correlated exposure data. Epidemiology 2007;18:199-207. 